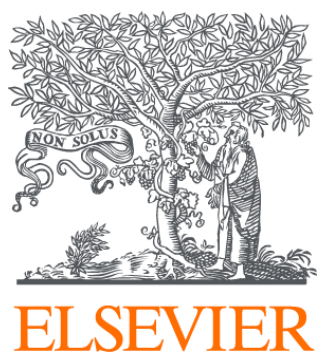

Since January 2020 Elsevier has created a COVID-19 resource centre with free information in English and Mandarin on the novel coronavirus COVID-

19. The COVID-19 resource centre is hosted on Elsevier Connect, the company's public news and information website.

Elsevier hereby grants permission to make all its COVID-19-related research that is available on the COVID-19 resource centre - including this research content - immediately available in PubMed Central and other publicly funded repositories, such as the WHO COVID database with rights for unrestricted research re-use and analyses in any form or by any means with acknowledgement of the original source. These permissions are granted for free by Elsevier for as long as the COVID-19 resource centre remains active. 


\title{
CD13/aminopeptidase $\mathrm{N}$ and murine cytomegalovirus infection
}

\author{
Laura M. Kasman* \\ Department of Microbiology and Immunology, Medical University of South Carolina, BSB-201, PO Box 250504, \\ 173 Ashley Avenue, Charleston, SC 29425, USA
}

Received 23 July 2004; returned to author for revision 11 October 2004; accepted 26 January 2005

\begin{abstract}
CD13/aminopeptidase $\mathrm{N}$ is a membrane-bound metalloproteinase implicated in human cytomegalovirus (HCMV) infection and pathogenesis. Anti-CD13 antibodies can neutralize HCMV infectivity, and HCMV viremia after bone marrow transplantation induces antiCD13 autoantibodies which correlate with development of chronic graft vs. host disease. We examined whether murine CD13/APN was similarly implicated in murine cytomegalovirus (MCMV) disease. MCMV infection did induce anti-CD13 antibodies in mice in a strainspecific manner. ICR and 129S mice developed high titers of anti-CD13 antibodies and anti-MCMV antibodies after MCMV infection, whereas CBA and CBAxC57BL/6 f1 hybrid mice produced antibodies against MCMV only. Unlike HCMV, no evidence was found for a correlation between host cell CD13/APN expression and infection, or for the presence of CD13/APN on MCMV particles, although APN inhibitors decreased MCMV plaque formation. Reproduction of CD13/APN autoantibody production in the murine system should make it possible to determine if these antibodies contribute to CMV pathogenesis.
\end{abstract}

(C) 2005 Elsevier Inc. All rights reserved.

Keywords: Cytomegalovirus; Aminopeptidase N; CD13; Autoantibodies; Autoimmunity; Mouse

\section{Introduction}

Cytomegaloviruses are beta-herpesviruses which establish life-long infections in their hosts. Several findings have implicated CD13, also known as aminopeptidase N (APN), in human cytomegalovirus (HCMV) infection and pathogenesis. In a series of bone marrow transplant patients, CD13/APN-specific autoantibodies were found only in patients with confirmed CMV disease after transplant and were highly associated with later development of chronic graft vs. host disease (cGVHD) (Soderberg et al., 1996a, 1996b). Patients seropositive for CMV but negative for the presence of virus did not develop anti-CD13/APN antibodies or cGVHD (Soderberg et al., 1996b). On the molecular level, several groups have shown that human CMV incorporates host cell proteins, one of which is CD13/ APN, into its viral envelope (Homman-Loudiyi et al., 2003;

\footnotetext{
* Fax: +1 8437922464 .

E-mail address: kasman1@musc.edu.
}

Michelson et al., 1989; Naucler et al., 1996; Wright et al., 1995). Some monoclonal antibodies raised against CD13/ APN can neutralize human CMV viral particles, and immunoblots of purified human CMV virions detect CD13/APN (Soderberg et al., 1993a). When viral particles are labeled with immunogold-anti-CD13 antibodies, the immunogold particles are later seen on the surface of infected cells (Giugni et al., 1996). Consistent with viral sequestration of CD13/APN, cell surface CD13/APN is down-regulated after human CMV infection in fibroblasts (Phillips et al., 1998). Association of CD13/APN with the viral particle has been suggested as a mechanism for the generation of anti-CD13/APN antibodies after CMV infection by autoimmunization (Naucler et al., 1996). That virusassociated CD13/APN is essential for HCMV infection is suggested by anti-CD13 antibody inhibition of infection (Soderberg et al., 1993a); however, human neuroblastoma cells lacking CD13 expression were susceptible to HCMV infection (Watanabe, 1998), and recently the epidermal growth factor receptor has been shown to be an important mediator of HCMV entry into cells (Wang et al., 2003). 
$\mathrm{CD} 13 / \mathrm{APN}$ is a membrane-bound metalloproteinase widely expressed on mammalian cells including monocytes, macrophages, endothelial cells, epithelial cells, and fibroblasts (Curnis et al., 2002; Phillips et al., 1998; PlakidouDymock et al., 1993; Riemann et al., 1999). It exists as a heavily glycosylated homodimer with a constitutively active proteinase activity external to the plasma membrane (Riemann et al., 1999). In addition to numerous tissuespecific functions, CD13/APN serves as a major receptor for type I coronaviruses (Breslin et al., 2003; Yeager et al., 1992), including possibly the SARS virus (Yu et al., 2003). More recently, CD13/APN has been shown to be an important mediator of angiogenesis when expressed on endothelial cells of nascent blood vessels (Bhagwat et al., 2001). Antibodies raised against CD13/APN and inhibitors of aminopeptidase activity both block angiogenesis in models of neovascularization (Pasqualini et al., 2000). This may have significance with regard to $\mathrm{CMV}$, since $\mathrm{CMV}$ infection is associated with many chronic vascular diseases (Borchers et al., 1999; Hamamdzic et al., 2002; Nieto et al., 1996; Pandey and LeRoy, 1998). CMV-induced anti-CD13/ APN antibodies may represent one mechanism by which the virus initiates vascular pathology.

Like most herpesviruses, cytomegaloviruses are species specific, but the link between CMV and vascular disease seen in humans has been reproduced repeatedly in mice infected with murine cytomegalovirus (Berencsi et al., 1998; Hamamdzic et al., 2001; Hummel et al., 2001; Presti et al., 1998). Therefore, in this study, we have examined whether CD13/APN is also implicated in MCMV infections in mice.

\section{Results}

MCMV infection induces anti-CD13/APN antibodies in a strain-specific manner

Four mouse strains were tested for the induction of MCMV and CD13/APN immunity after MCMV infection. These strains, CBA, CBAxC57BL/6 f1 hybrids, ICR, and $129 \mathrm{~S}$ mice deficient in the interferon gamma receptor (IFNgR-/-), vary in their $\mathrm{H}-2$ haplotype and in their reported resistance to MCMV infection. Groups of 4-6 animals of each of these strains were infected with $10^{5} \mathrm{PFU}$ MCMV by IP injection, which is a sublethal dose in adult animals for all strains. Serum was collected after 14 days and analyzed by ELISA for IgG antibodies against MCMV and mouse CD13/APN. All strains had similar levels of IgG antibodies directed against MCMV (Fig. 1). However, antiCD13/APN antibodies were detected only in the sera from ICR and 129S-IFNgR - / - mice, and no detectable antibodies against $\mathrm{CD} 13$ were found in sera from $\mathrm{CBA}$ or B6 hybrid mice. Anti-CD13 antibodies in humans were reported in people who developed HCMV viremia while in an immunocompromised state. In order to test whether an immunocompromised state would be associated with induction of higher

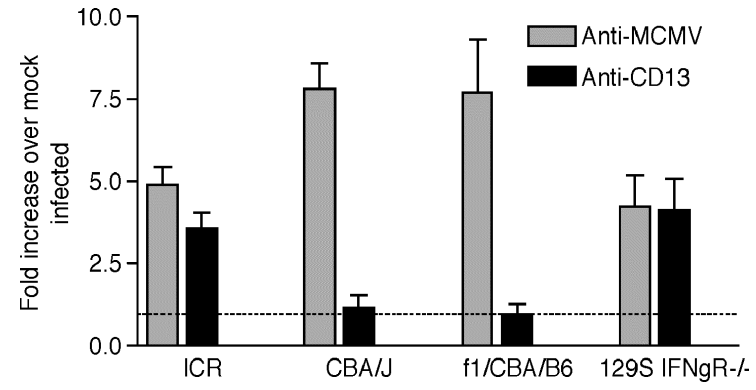

Fig. 1. MCMV infection induces anti-CD13 antibodies in susceptible strains of mice. Groups of four ICR, CBA/J, B6/CBA f1 hybrids, and interferon gamma receptor knock out mice on a $129 \mathrm{~S}$ background were infected by intraperitoneal injection with $10^{5} \mathrm{PFU}$ MCMV. Sera collected 14 days postinfection were assayed in duplicate at a 1:10 dilution for anti-MCMV (gray bars) and anti-CD13 (black bars) antibodies by ELISA. Figure is representative of two similar experiments. Dashed line indicates mean antibody response in mock-infected mice.

levels anti-CD13 antibodies in mice, cyclosporine A was used to induce an immunocompromised state in ICR mice. Three groups of 6 ICR mice were treated with either cyclosporine A alone, cyclosporine $\mathrm{A}$ and $10^{5} \mathrm{PFU} \mathrm{MCMV}$, or $10^{5} \mathrm{PFU}$ $\mathrm{MCMV}+$ mock cyclosporine A injections. Mice treated with cyclosporine A and MCMV had increased signs of illness over those given MCMV alone (not shown). However, levels of antibodies to both MCMV and CD13 were not significantly different between the two groups (Fig. 2).

\section{Cell surface APN activity and MCMV susceptibility}

To investigate whether expression of murine CD13/APN correlates with MCMV susceptibility as reported for HCMV (Soderberg et al., 1993a, 1993b), five murine cell lines were characterized with respect to MCMV progeny production and cell surface aminopeptidase N/CD13 activity. NIH 3T3, 3T12, and primary mouse embryonic fibroblasts (MEF) are all fibroblast in phenotype. Py-41 and SVEC-4 cells are mouse endothelial cell lines immortalized by the polyoma $\mathrm{T}$ antigen and the SV40 T-antigen, respectively (Dubois et al., 1991; O'Connell and Edidin, 1990). In an assay of MCMV progeny production after inoculation at low multiplicity of infection, marked differences were seen between cell lines in susceptibility to productive MCMV infection (Fig. 3A). Peak MCMV titers in supernatants from the three fibroblast lines were close to $10^{6} \mathrm{PFU} / \mathrm{ml}$, while SVEC-4 cells produced $10^{5} \mathrm{PFU} / \mathrm{ml}$, and Py-41 cells produced less than $1000 \mathrm{PFU} / \mathrm{ml}$. Similar relative results were seen in a plaque assay on the five cell lines (Fig. 4).

In contrast to human cells, attempts to compare CD13/ APN expression on murine cell lines by immunological methods were unsuccessful. Two commercially available antibodies specific for murine CD13/APN failed to recognize any proteins on Western blotted cell extracts (not shown). Immunofluorescent flow cytometry staining of cell surface proteins with antibody R3-242 conjugated to phycoerythrin showed that CD13/APN was present on both endothelial and fibroblast cells. However, relative expression 


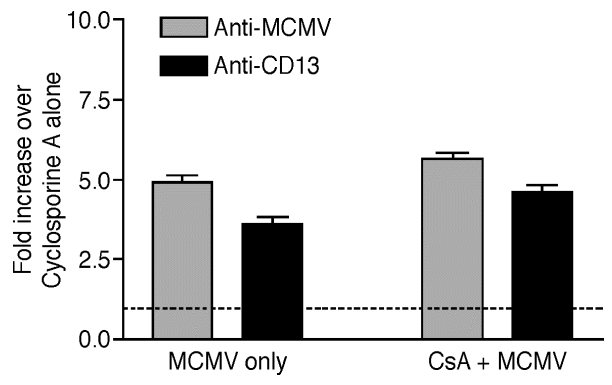

Fig. 2. Effect of cyclosporine A treatment on anti-CD13 antibody induction by MCMV infection. Sera from female ICR mice were analyzed for antiMCMV (gray bars) and anti-CD13 (black bars) IgG antibodies by ELISA. Groups of 6 mice were injected with (1) cyclosporine A (CsA) once daily for 15 days, (2) diluent once daily for 15 days and inoculation with $10^{5} \mathrm{pfu}$ MCMV-lacZ on day 2, (3) CsA daily for 15 days and an equivalent amount of uninfected salivary gland extract on day 2. All treatments were by intraperitoneal injection. Sera were collected on day 15, diluted 1:10 in saline, and analyzed in duplicate. Results are expressed as fold increase in antibody levels relative to the mean response of mice treated with CsA alone.

cannot be compared by this method in different cell types, so an alternative to immunological techniques was used.

To quantitate cell surface CD13/APN, APN enzymatic activity was measured by a standard procedure using the colorimetric substrate, ala- $p$-nitroanalide hydrochloride (Plakidou-Dymock et al., 1993). To determine the linearity of the assay with adherent cells, Py-41, SVEC-4, 3T3, 3T12, and MEF cells were plated at densities of 5000, 10,000, 20,000 , and 40,000 cells/well and incubated $18 \mathrm{~h}$ later as adherent monolayers with APN substrate. Substrate conversion was directly proportional to the number of cells in all cell lines (Fig. 3B), with slight decreases at higher densities as expected. Cells were plated at 10,000 cells/well in 96-well plates for subsequent assays. To compare amounts of cell-surface CD13/APN exposed to MCMV in a standard inoculation with subsequent plaque formation, parallel sets of 6 wells of each cell type were assayed for APN enzyme activity, or inoculated with MCMV-lacZ and incubated a further $48 \mathrm{~h}$, followed by staining and counting of plaques. Three dilutions of MCMV-lac $\mathrm{Z}$ virus were used in three sets of 6 wells to detect the range of susceptibilities observed. There was no correlation between CD13/APN expression and MCMV plaque formation (Fig. 4). CD13/ APN enzyme activity was similar on all five cell lines whereas plaque formation and progeny virus production were markedly different, especially between endothelial and fibroblast cells. Whether or not CD13/APN is necessary for MCMV infection cannot be determined from this experiment since none of the murine cell lines tested were negative for CD13/APN, however, CD13 expression is clearly not sufficient for productive MCMV infection of Py41 endothelial cells.

\section{APN inhibitors reduce MCMV infection}

EDTA and 1,10-phenanthroline monohydrate are both APN inhibitors which act by chelating divalent metals. At effective concentrations, both have the effect of causing adherent cells, such as $3 \mathrm{~T} 3$ cells, to lift. Therefore, cells were purposely incubated with MCMV-lacZ virus in suspension in the presence or absence of APN inhibitor. After 1-h incubation, cells were washed clean of unbound virus and inhibitor and plated. Plaques visualized at $48 \mathrm{~h}$ post-infection with X-Gal were counted in 6 parallel wells/ treatment. Both EDTA and 1,10-phenanthroline significantly decreased the number of plaques formed on treated cells in a dose-dependent manner (Fig. 5A). Exposure to concentrations of 1,10-phenanthroline above $1.5 \mathrm{mM}$ or EDTA above $5 \mathrm{mM}$ for $1 \mathrm{~h}$ killed 3T3 cells. In contrast, when virus was exposed to the same inhibitor concentrations for $30 \mathrm{~min}$ prior to dilution and inoculation of cells,
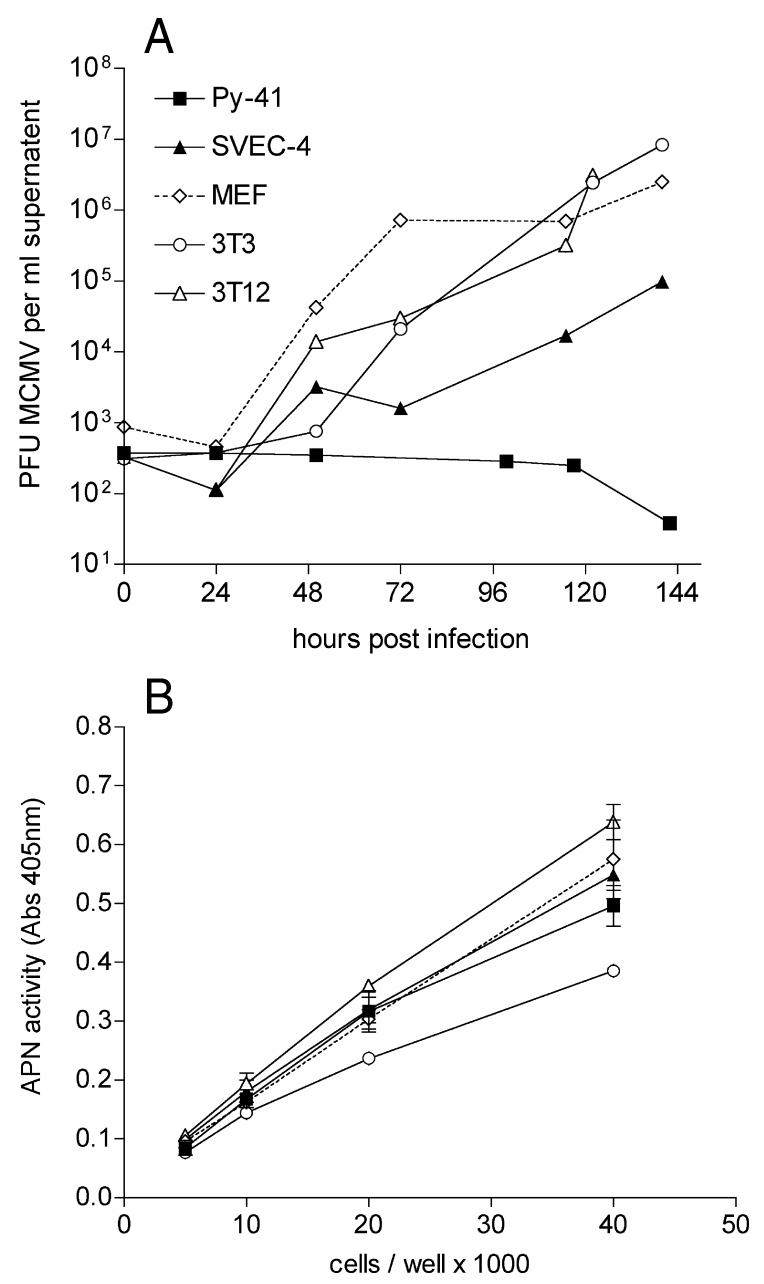

Fig. 3. Characterization of five murine cell lines with respect to MCMV progeny production and cell surface aminopeptidase N/CD13 activity. (A) Monolayers of murine endothelial cell lines Py-41 and SVEC-4, and murine fibroblast cell lines 3T3 and 3T12, and primary embryonic fibroblasts (MEF), were infected with salivary gland-derived MCMV-lacZ at an MOI of 0.1 . Aliquots of supernatant collected approximately every $24 \mathrm{~h}$ were tittered on 3 T3 fibroblasts. Data shown are combined results of two independent experiments. (B) Measurement of cell surface aminopeptidase $\mathrm{N}$ activity by ala- $p$-nitroalanine cleavage. Actively growing cells of each type were plated at four different densities $16 \mathrm{~h}$ prior to incubation with colorimetric APN substrate ala- $p$-nitroalanine. Each data point is the average of absorbance readings of 6 wells after 3 -h incubation at $37{ }^{\circ} \mathrm{C}$. 


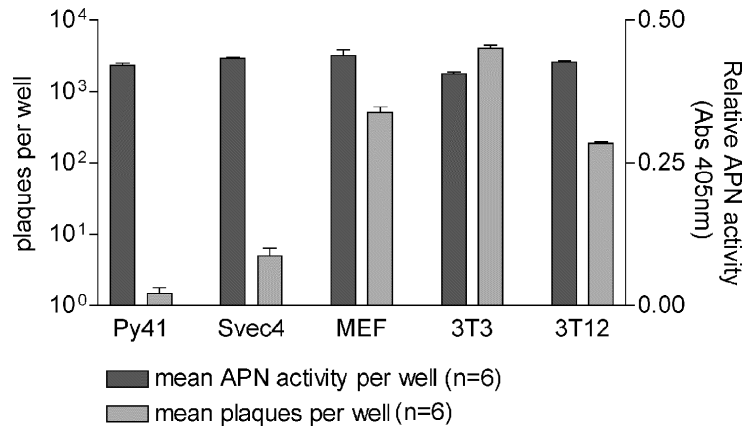

Fig. 4. MCMV susceptibility does not correlate with cell surface aminopeptidase N/CD13 activity. Five murine cell lines (Py-41, SVEC-4, 3T3, 3T12) and primary embryonic fibroblasts (MEF) were each seeded into wells of a 96-well plate at 10,000 cells/well. After being allowed to adhere overnight, six wells of each cell type were immediately assayed for cell surface APN activity, and parallel wells of each cell type were exposed to MCMV-lac Z virus. After 2-h incubation with virus, inoculum was replaced with fresh medium. Two days later, plaques were visualized by $\mathrm{X}-\mathrm{Gal}$ overlay. The titer (light bars) is expressed as mean plaques per well. Relative APN activity (dark bars) is indicated in absorbance units on the right $y$-axis. The figure is representative of two identical experiments.

little effect was seen on plaque formation, indicating that the MCMV particles themselves were not dependent on metalloproteinase activity for stability or activity (Fig. 5B).

\section{Effect of anti-CD13/APN antibody on MCMV infection in vitro}

CD13/APN has been detected with antibodies in HCMV viral envelopes and some anti-CD13/APN antibodies neutralize human $\mathrm{CMV}$ and prevent infection in vitro (Giugni et al., 1996). Both anti-murine CD13/APN antibodies were tested for their ability to block MCMV infection of NIH3T3 cells. Neither preincubation of antibody with virus nor antibody with host cells reduced plaque formation (Figs. 5A and B). Since not all CD13/APN epitopes give rise to neutralizing antibodies of HCMV (Giugni et al., 1996), this did not rule out a role for APN in MCMV infection. Strangely, the presence of antibody R3242 during infection significantly enhanced the number and size of plaques formed on NIH3T3 cells (Fig. 5A), while antibody H-300 had a similar effect when preincubated with virus (Fig. 5B). Although antibody-dependent enhancement of viral infection is well documented, it generally requires antibodies from the same species as the host cells and depends on $\mathrm{Fc}$ or complement receptor expression of the host cell (Tirado and Yoon, 2003). R3-242 and H-300 are rat and rabbit antibodies, respectively, and NIH 3 T3 cells are not known to express Fc receptors.

Two other methods were used to attempt to detect APN incorporation into MCMV viral particles. APN activity assays of salivary gland-derived virus vs. uninfected salivary gland supernatants were compared and found to be identical when normalized for protein content (Table 1). In addition, salivary gland-derived MCMV, tissue culturederived MCMV, relevant uninfected control extracts, and
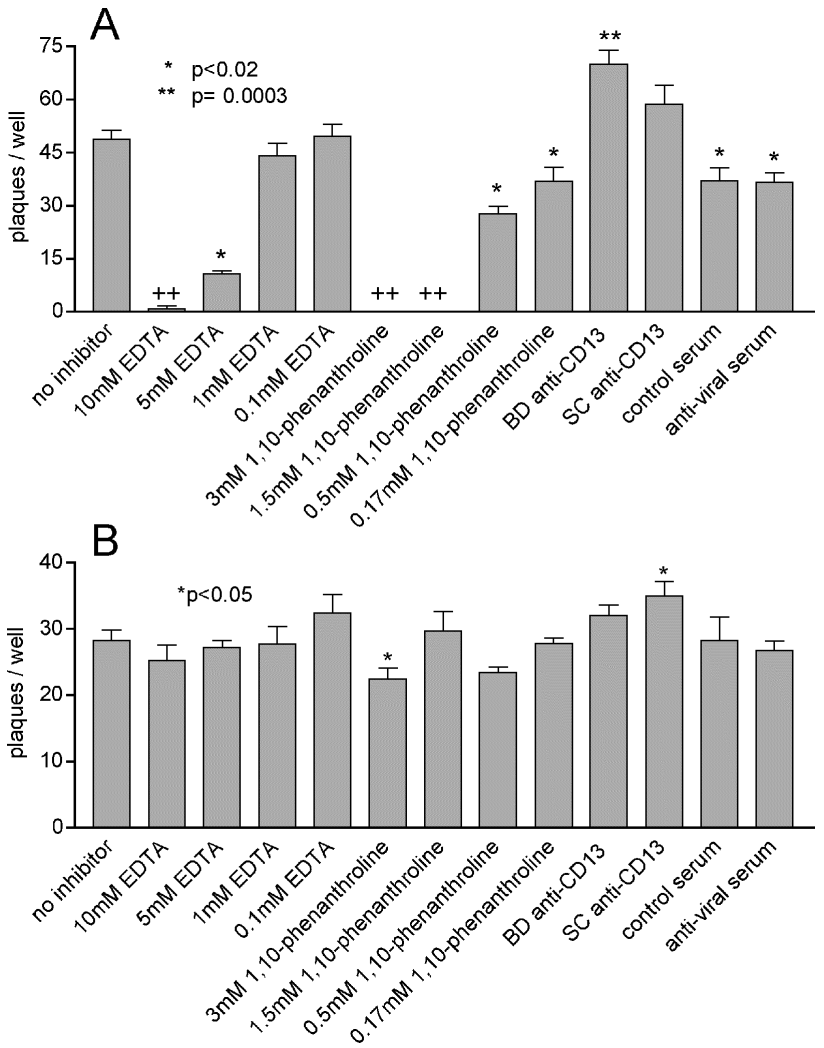

Fig. 5. APN inhibitors reduce MCMV infection, but not virus viability. (A) NIH 3 T3 cells $\left(6 \times 10^{4}\right)$ were incubated in suspension with MCMV-lacZ plus or minus APN inhibitors $(10 \mathrm{mM}, 5 \mathrm{mM}, 1 \mathrm{mM}$ or $0.1 \mathrm{mM}$ EDTA, or $3 \mathrm{mM}, 1.5 \mathrm{mM}, 0.5 \mathrm{mM}$, or $0.17 \mathrm{mM}$ 1,10-phenanthroline) or antibodies (R3-242, sc-15360) as indicated. After $30 \mathrm{~min}$ at $37^{\circ} \mathrm{C}$, cells were washed and resuspended in complete medium, and seeded at $10^{4}$ cells/well into 6 wells of a 96-well plate. Plaques were visualized in each well by X-Gal overlay $72 \mathrm{~h}$ post-infection. ++ Indicates cytotoxic inhibitor concentration. * Indicates a significant difference from untreated control. (B) Virus pretreatment with APN inhibitors: $10^{5}$ PFU MCMV-lacZ were incubated with inhibitors or anti-CD13 antibodies as indicated for $30 \mathrm{~min}$, diluted 300 -fold, and used to infect NIH 3 T3 cells $\left(6 \times 10^{4} / 100 \mu 1\right)$ in suspension. Plaques were visualized as in A. A representative of three similar experiments is shown.

murine brush border membrane vesicles (BBMV) were spotted onto nitrocellulose at several dilutions and probed with antibody R3-242. The antibody readily detected an 80 -fold dilution of BBMV, while failing to detect any protein in the viral or control preparations at any dilution (data not shown). In summary, no evidence for incorporation of CD13/APN into MCMV viral envelopes was found.

Table 1

APN activity in MCMV virus preparation

\begin{tabular}{ll}
\hline & $\begin{array}{l}\text { APN activity (substrate } \\
\text { cleaved } / \mathrm{mg} \text { protein) }\end{array}$ \\
\hline BBMV $(\mu \mathrm{mol} / \mathrm{min})$ & 53.7 \\
$\begin{array}{l}\text { Uninfected salivary gland homogenate } \\
(\mu \mathrm{mol} / \mathrm{min})\end{array}$ & 3.0 \\
$\begin{array}{l}\text { MCMV-infected salivary gland homogenate } \\
(\mu \mathrm{mol} / \mathrm{min})\end{array}$ & 2.8 \\
\hline
\end{tabular}




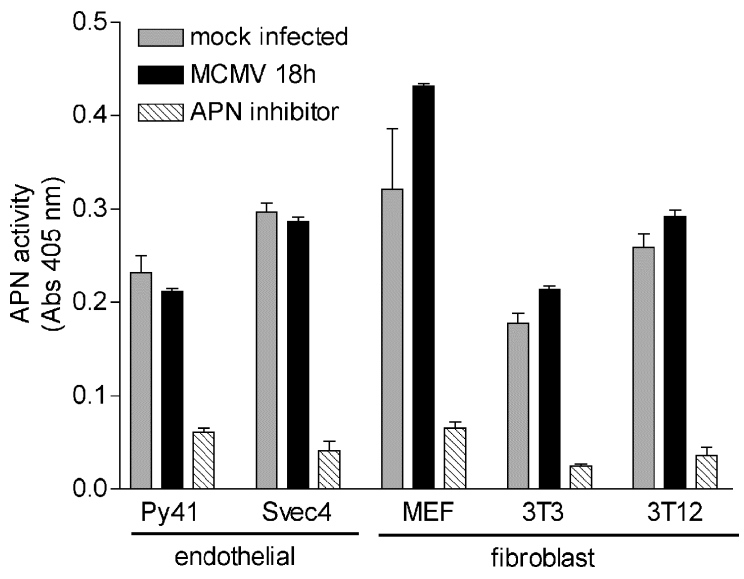

Fig. 6. Cell surface APN activity is not significantly altered by MCMV infection. Parallel wells of each cell line were mock infected (gray bars) or infected with MCMV-lacZ at an MOI of 10 (black bars). After $18 \mathrm{~h}$ of infection, cell surface APN activity was measured by ala- $p$-nitroalanine cleavage. Addition of APN inhibitor 1,10-phenanthroline (striped bars) with substrate was used as a positive control.

\section{Cell surface CD13/APN activity is not significantly altered by MCMV infection}

Human CMV has been reported to reduce CD13/APN expression in infected human fibroblasts approximately $30 \%$ within $24 \mathrm{~h}$ of infection, as determined by immunofluorescence staining and APN activity assays. Expression is further reduced to up to $50 \%$ over the next 2-3 days of infection and appears to be due to ER retention and degradation of the CD13 protein (Phillips et al., 1998). To determine if MCMV has a similar effect on murine CD13/ APN, cells from all five murine cell lines were assayed for APN activity 18 and $72 \mathrm{~h}$ after infection. Cells were infected with an MOI of approximately 20, or mock infected with an equivalent concentration of salivary gland homogenate from uninfected mice. In contrast to human fibroblasts, all three mouse fibroblast lines had slightly (10-30\%) increased APN cell surface activity $18 \mathrm{~h}$ after infection, while mouse endothelial cell lines Py-41 and SVEC-4 had slightly (39\%) decreased APN activity (Fig. 6). At 72 h, cell death was apparent in all infected wells, and APN activity was reduced compared to mock-infected wells, however, APN activity per well was increased compared to $18 \mathrm{~h}$ post-infection in all cases due to increases in cell number (not shown). Whole cell ELISA gave similar results, except that differences between infected and non-infected cells were even smaller (not shown). Therefore, unlike human CMV infection, MCMV infection seems to have only a small effect if any on CD13/APN expression in fibroblasts and endothelial cells, which varies according to cell type.

\section{Discussion}

In agreement with previous reports that human CMV infection induces anti-CD13/APN antibodies in immuno- compromised individuals, we found that murine CMV induced antibodies against murine CD13/APN in susceptible strains of mice. However, treatment of susceptible mice with the immunosuppressant Cyclosporine A did not significantly increase anti-CD13/APN antibody production, suggesting that immunosuppression is not necessary for induction of these autoantibodies. Whether immunocompetent humans can develop anti-CD13 antibodies after CMV infection has not been investigated to our knowledge.

The strain producing the highest ratio of anti-CD13 to anti-MCMV antibodies was 129S-IFNgR-/- which has been used as a model of persistent CMV infection because the mice actively shed virus for at least 6 months after infection (Presti et al., 1998). In contrast, CBA and CBA/B6 hybrids are known to be genetically resistant to MCMVinduced mortality. MCMV resistance in mice is determined largely by the gene $c m v 1$, which encodes Ly $49 \mathrm{H}$, an NK cell receptor which is activated by the MCMV protein m157 (Arase et al., 2002; Lee et al., 2002; Swihart et al., 1995). MCMV-resistant mouse strains have peak spleen viral titers that are 2-3 logs lower and $\mathrm{LD}_{50}$ doses that are 1-2 logs higher than susceptible strains. CBA and $\mathrm{C} 57 \mathrm{BL} / 6$ mice express Ly49H on their NK cells and are resistant whereas 129S mice do not express Ly49H and are susceptible. The ICR mice were not genotyped for cmv1 and were intermediate in their susceptibility to MCMV morbidity, as well as autoantibody production. This suggests that high spleen titers may be associated with development of antiCD13 antibodies. MHC type does not seem to be correlated with anti-CD13 antibody production in our experiments, since the haplotype $\mathrm{H}-2^{\mathrm{b}}$ is shared by both productive $129 \mathrm{~S}$ and non-productive $\mathrm{C} 57 \mathrm{BL} / 6$ hybrid strains.

In the human system, it has been proposed that antiCD13/APN antibodies occur as a result of autoimmunization by CD13/APN incorporated into HCMV viral envelopes. We were unable to find evidence of CD13/APN incorporation into MCMV viral particles, but this may be due to the limited variety of anti-CD13 antibodies available for the murine system. Neither antibody tested was able to detect CD13/APN on Western blots, and sc-15360 failed to detect CD13/APN even in native BBMV containing APN readily detected at a 1:80 dilution by antibody R3-242. It is possible that a more comprehensive array of anti-murine CD13/APN antibodies would have detected CD13/APN in MCMV particles or have been able to neutralize MCMV infectivity, however, APN enzymatic assays also failed to detect a difference between virus and control lysates. Cellsurface CD13/APN also did not correlate with MCMV susceptibility. And while inhibitors of APN enzyme activity did reduce MCMV plaque formation, the inhibitors used are not especially specific for APN. Taken together, a role for CD13/APN as an entry mediator for MCMV seems unlikely.

Virus-induced autoantibodies, including anti-endothelial cell and anti-phospholipid antibodies following cytomegalovirus infections, have been demonstrated before in both 
mice and humans (Bartholomaeus et al., 1988; Cheng and Khairullah, 1997; Fairweather et al., 1998; Hebart et al., 1996; Hiemstra et al., 2001; Lipes et al., 2002; Lunardi et al., 2000). With regard to the mechanisms of their induction, it has been proposed that these antibodies are directed against viral antigens which by coincidence resemble host cellular proteins (molecular mimicry), or that virus-induced tissue damage results in immunological processing and recognition of self-antigens normally sequestered from immune surveillance (Lawson, 2000; Naucler et al., 1996). In this study, several factors argue against a simple case of molecular mimicry. Although human and mouse CD13/APN are $76 \%$ identical at the amino acid level (Chen et al., 1996), HCMV and MCMV share less homology, CD13/APN is glycosylated and genetically polymorphic (Vijgen et al., 2004; Wentworth and Holmes, 2001), and predicted MHC presentable peptides differ with MHC haplotype and species. Therefore, the likelihood of a single epitope common to both hosts, both viruses, and presentable by several MHC types seems small. Determination of the CD13/APN epitopes recognized by the sera of different mouse strains is currently underway and may allow identification of a viral antigen inducer if molecular mimicry is leading to the production of anti-CD13/APN antibodies.

Immunological processing of self-antigens as a result of virus-induced tissue damage is more difficult to examine. The association of CD13/APN autoantibodies with conditions favoring high in vivo titers is consistent with this mechanism. However, CD13/APN cannot credibly be described as a sequestered self-antigen in that it is normally expressed on the surface of numerous cell types throughout the body and is present in normal serum (Kawai et al., 2001). Therefore, neither of the general mechanisms thought to give rise to virus-induced autoantibodies seems likely in the case of MCMV-induced CD13/APN antibodies.

CMV seropositivity has long been associated with a variety of vasculopathies including atherosclerosis and systemic sclerosis (Borchers et al., 1999; Hamamdzic et al., 2002; Nieto et al., 1996; Pandey and LeRoy, 1998). CMV infection has also long been recognized as a serious complication of bone marrow and solid organ transplantation because of vascular sequelae (Borchers et al., 1999; Matthes-Martin et al., 1998). CMV viremia after bone marrow transplant is associated with a significant increase in chronic graft vs. host disease (cGVHD), which shares many features in common with the autoimmune disease scleroderma, and begins as an inflammation and destruction of small blood vessels (Pandey and LeRoy, 1998). CMV viremia after solid organ transplant results in exacerbation of transplant vascular sclerosis leading to chronic graft rejection (Borchers et al., 1999). The mechanism(s) by which CMV produces these negative outcomes is not understood, however, reduction of viral titers with anti-viral drugs decreases cGVHD, CMV-associated rejection, and vascular stenosis (Koskinen et al., 1999; Matthes-Martin et al., 1998). Autoantibodies targeting an angiogenic factor such as CD13/APN may be one mechanism by which CMV could mediate these effects. The two mouse strains found to produce anti-CD13/APN antibodies in this study are also the strains most susceptible to CMV-induced vascular disease (Berencsi et al., 1998; Hamamdzic et al., 2001; Presti et al., 1998). The fact that CMV induction of anti-CD13/APN antibodies is now reproduced in mice should make it possible to examine whether such antibodies play a part in CMV-induced vascular pathology.

\section{Materials and methods}

\section{Cells, medium, antibodies, FACS, immunoblotting}

SVEC-4, NIH 3T3, and NIH 3T12 cells were obtained from the ATCC (Rockville, MD) and grown as recommended. Mouse embryo fibroblasts were prepared from Balb/c mouse embryos as described (Brune et al., 1999). Py-41 cells were generously provided to our lab by V.L. Bautch (University of North Carolina, Chapel Hill, NC) and propagated on gelatin-coated plates (Biocoat, Becton Dickenson) in low glucose DMEM $+10 \%$ fetal calf serum (Dubois et al., 1991). All cells were grown in medium containing Gibco antibiotic-antimycotic solution (Invitrogen, Inc.). Two anti-murine CD13 antibodies were used: R3242, a rat anti-mouse monoclonal (Research Diagnostics, Inc.), and sc-15360, a rabbit IgG (Santa Cruz Biotechnologies, Inc.).

\section{Virus and plaque assays}

A recombinant murine cytomegalovirus expressing the Escherichia coli lacZ gene (RM461), generously provided by Edward Mocarski (Stanford University), was used in all experiments. This virus expresses lac $\mathrm{Z}$ mid to late infection so that the enzyme accumulates throughout infection (Stoddart et al., 1994). Salivary gland passaged virus was prepared as described previously (Hamamdzic et al., 2001) and titered on 3T3 cells. Plaque assays were performed in 96-well plates. Briefly, NIH 3T3 cells were plated the day before the assay at $10^{4}$ cells/well. Dilutions of virus were made in minimal essential medium containing $0.1 \%$ porcine gelatin, and $20 \mu \mathrm{l}$ diluted virus/well was incubated with cells at $37{ }^{\circ} \mathrm{C}$ for $2 \mathrm{~h}$. Inoculum was aspirated and cells covered with $100 \mu \mathrm{l} /$ well $0.6 \%$ methylcellulose in complete medium. After incubation for 48-72 h, $100 \mu 110 \%$ neutral-buffered formalin was added to each well for $10 \mathrm{~min}$, followed by three washes with phosphate-buffered saline to remove methylcellulose. Plaques were visualized by overlay with XGal (5-bromo-4-chloro-3-indolyl-beta-D-galactopyranoside) and counted under a dissecting scope. Inoculations of mice were by intraperitoneal injection of salivary gland-passaged virus in a volume of $0.2 \mathrm{ml}$ using minimal essential medium as a diluent. 


\section{Reagents}

Cyclosporine A was purchased from LC laboratories (Woburn, MA) and $14 \mathrm{mg}$ was solubilized in $0.5 \mathrm{ml} \mathrm{100 \%}$ ethanol and $0.2 \mathrm{ml}$ Tween 80 , then diluted to $2 \mathrm{mg} / \mathrm{ml}$ in PBS for injection. Ethylenediaminetetraacetic acid $(0.5 \mathrm{M}$ solution, $\mathrm{pH}$ 8.0) was purchased from GibcoBRL (Cat. No. 15575-038). 1,10-Phenanthroline monohydrate (P 9375) and L-alanine- $p$-nitroanilide hydrochloride were purchased from Sigma.

\section{Mice}

CBA, CBA/C57BL6 f1 hybrids, and 129S IFNgR-/mice were obtained from Jackson Laboratories (Bar Harbor, Maine). ICR mice were purchased from Harlan Laboratories. All experiments described in this study conform with "The guide for the Care and Use of Laboratory Animals" published by the US National Institutes of Health (NIH Publication No. 85-23, revised 1996) and were approved by the MUSC institutional committee for the care and use of laboratory animals. Food and water were provided ad libitum. All mice were housed in hepa-filtered cages in the approved animal facility and monitored daily.

\section{Crude aminopeptidase $N$ preparation}

To prepare murine CD13, small intestines from nine ICR mice were dissected free of mesenteric fat and flushed clean with cold saline. The drained tissue was homogenized in 9 volumes cold sucrose buffer (2 mM Tris, $\mathrm{pH} 6.8,50 \mathrm{mM}$ sucrose) with a Tissumizer SDT-1810 (Tekmar, Cincinnati $\mathrm{OH})$ for 1 min keeping the tube on ice. Brush border membrane vesicle formation was induced by adding $\mathrm{CaCl}_{2}$ to a final concentration of $10 \mathrm{mM}$ and stirring continuously for $15 \mathrm{~min}$ at $4{ }^{\circ} \mathrm{C}$. Debris was pelleted by centrifugation at $4000 \times g$ for $10 \mathrm{~min}$. BBMVs were pelleted by centrifugation of the supernatant for $30 \mathrm{~min}$ at $27,000 \times \mathrm{g}$ at $4{ }^{\circ} \mathrm{C}$. BBMVs were resuspended in a small volume of sucrose buffer and stored at $-80{ }^{\circ} \mathrm{C}$. Gut APN has been shown to be serologically identical to CD13/APN expressed in splenocytes and macrophage (Riemann et al., 1999).

\section{Aminopeptidase $N$ activity assays}

Aminopeptidase $\mathrm{N}$ activity assays were performed by incubating living adherent cells at $37{ }^{\circ} \mathrm{C}$ in phosphatebuffered saline $(\mathrm{pH}$ 7.2) containing $6 \mathrm{mM}$ alanine- $p$ nitoanilide hydrochloride. Absorbance was read at 1-h intervals at $405 \mathrm{~nm}$.

\section{ELISA}

ELISAs were performed on Reacti-Bind maleic anhydride activated clear 96-well plates (Pierce, Rockford, IL). Viral antigen for ELISA was intact MCMV grown in tissue culture and prepared by ultracentrifugation through sucrose by standard protocol (Brune et al., 1999). The partially purified virus was diluted in phosphate-buffered saline to a protein concentration of $10 \mathrm{mg} / \mathrm{ml}$ and plates were coated using $50 \mu \mathrm{l} / \mathrm{well}$ overnight at $4{ }^{\circ} \mathrm{C}$. For detection of antiCD13/APN antibodies, BBMVs in sucrose buffer were diluted in PBS to a protein concentration of $1.5 \mathrm{mg} / \mathrm{ml}$, and $50 \mu \mathrm{l} /$ well was used to coat plates overnight at $4{ }^{\circ} \mathrm{C}$. Blocking of binding of rabbit antibody sc-15360 and rat monoclonal R3-242 by mouse sera demonstrated specificity of antibodies in sera of MCMV-infected mice for CD13/ APN. Whole cell ELISAs were also performed to measure cell surface CD13 expression on the murine cell lines. Cells were plated at $10^{4}$ cells/well and incubated with R3-242 anti-CD13 antibody the next day after fixation with $2 \%$ glutaraldehyde. Horseradish peroxidase-conjugated secondary antibodies were used and detected by incubation with 1-Step ABTS (Pierce).

\section{Acknowledgments}

The author is grateful to Dr. Kenneth Chavin for the cyclosporine A protocol and Dr. Damir Hamamdzic for helpful discussions. This research was funded by a grant from the RGK Foundation.

\section{References}

Arase, H., Mocarski, E.S., Campbell, A.E., Hill, A.B., Lanier, L.L., 2002. Direct recognition of cytomegalovirus by activating and inhibitory NK cell receptors. Science 296 (5571), 1323-1326.

Bartholomaeus, W.N., O'Donoghue, H., Foti, D., Lawson, C.M., Shellam, G.R., Reed, W.D., 1988. Multiple autoantibodies following cytomegalovirus infection: virus distribution and specificity of autoantibodies. Immunology 64 (3), 397-405.

Berencsi, K., Endresz, V., Klurfeld, D., Kari, L., Kritchevsky, D., Gonczol, E., 1998. Early atherosclerotic plaques in the aorta following cytomegalovirus infection of mice. Cell Adhes. Commun. 5 (1), 39-47.

Bhagwat, S.V., Lahdenranta, J., Giordano, R., Arap, W., Pasqualini, R., Shapiro, L.H., 2001. CD13/APN is activated by angiogenic signals and is essential for capillary tube formation. Blood 97 (3), 652-659.

Borchers, A.T., Perez, R., Kaysen, G., Ansari, A.A., Gershwin, M.E., 1999. Role of cytomegalovirus infection in allograft rejection: a review of possible mechanisms. Transplant Immunol. 7 (2), 75-82.

Breslin, J.J., Mork, I., Smith, M.K., Vogel, L.K., Hemmila, E.M., Bonavia, A., Talbot, P.J., Sjostrom, H., Noren, O., Holmes, K.V., 2003. Human coronavirus 229E: receptor binding domain and neutralization by soluble receptor at 37 degrees C. J. Virol. 77 (7), 4435-4438.

Brune, W., Hengel, H., Koszinowski, U.H., 1999. A mouse model for cytomegalovirus infection. In: Coligan, J.E., (Eds.), Current Protocols in Immunology, vol. Suppl. 32. John Wiley and Sons, Inc., New York, pp. 19.7.1-19.7.13 (3 vols).

Chen, H., Kinzer, C.A., Paul, W.E., 1996. p161, a murine membrane protein expressed on mast cells and some macrophages, is mouse CD13/aminopeptidase N. J. Immunol. 157 (6), 2593-2600.

Cheng, H.M., Khairullah, N.S., 1997. Induction of antiphospholipid autoantibody during cytomegalovirus infection. Clin. Infect. Dis. 25 (6), $1493-1494$.

Curnis, F., Arrigoni, G., Sacchi, A., Fischetti, L., Arap, W., Pasqualini, R., 
Corti, A., 2002. Differential binding of drugs containing the NGR motif to $\mathrm{CD} 13$ isoforms in tumor vessels, epithelia, and myeloid cells. Cancer Res. 62 (3), 867-874.

Dubois, N.A., Kolpack, L.C., Wang, R., Azizkhan, R.G., Bautch, V.L., 1991. Isolation and characterization of an established endothelial cell line from transgenic mouse hemangiomas. Exp. Cell Res. 196 (2), $302-313$

Fairweather, D., Lawson, C.M., Chapman, A.J., Brown, C.M., Booth, T.W., Papadimitriou, J.M., Shellam, G.R., 1998. Wild isolates of murine cytomegalovirus induce myocarditis and antibodies that cross-react with virus and cardiac myosin. Immunology 94 (2), 263-270.

Giugni, T.D., Soderberg, C., Ham, D.J., Bautista, R.M., Hedlund, K.O., Moller, E., Zaia, J.A., 1996. Neutralization of human cytomegalovirus by human CD13-specific antibodies. J. Infect. Dis. 173 (5), $1062-1071$.

Hamamdzic, D., Harley, R.A., Hazen-Martin, D., LeRoy, E.C., 2001. MCMV induces neointima in IFN-gammaR-/- mice: intimal cell apoptosis and persistent proliferation of myofibroblasts. BMC Musculoskelet. Disord. 2 (1), 3.

Hamamdzic, D., Kasman, L.M., LeRoy, E.C., 2002. The role of infectious agents in the pathogenesis of systemic sclerosis. Curr. Opin. Rheumatol. 14 (6), 694-698.

Hebart, H., Einsele, H., Klein, R., Fischer, I., Buhler, S., Dietz, K., Jahn, G., Berg, P.A., Kanz, L., Muller, C.A., 1996. CMV infection after allogeneic bone marrow transplantation is associated with the occurrence of various autoantibodies and monoclonal gammopathies. Br. J. Haematol. 95 (1), 138-144.

Hiemstra, H.S., Schloot, N.C., van Veelen, P.A., Willemen, S.J., Franken, K.L., van Rood, J.J., de Vries, R.R., Chaudhuri, A., Behan, P.O., Drijfhout, J.W., Roep, B.O., 2001. Cytomegalovirus in autoimmunity: $\mathrm{T}$ cell crossreactivity to viral antigen and autoantigen glutamic acid decarboxylase. Proc. Natl. Acad. Sci. U.S.A. 98 (7), 3988-3991.

Homman-Loudiyi, M., Hultenby, K., Britt, W., Soderberg-Naucler, C., 2003. Envelopment of human cytomegalovirus occurs by budding into Golgi-derived vacuole compartments positive for gB, Rab 3, TransGolgi network 46, and Mannosidase II. J. Virol. 77 (5), 3191-3203.

Hummel, M., Zhang, Z., Yan, S., DePlaen, I., Golia, P., Varghese, T., Thomas, G., Abecassis, M.I., 2001. Allogeneic transplantation induces expression of cytomegalovirus immediate-early genes in vivo: a model for reactivation from latency. J. Virol. 75 (10), 4814-4822.

Kawai, M., Hara, Y., Miyazato, I., Hosaki, S., 2001. Novel, aberrantly truncated isoform of serum $\mathrm{CD} 13$ in a family with high serum aminopeptidase N (CD13) activity. Clin. Chem. 47 (2), 223-230.

Koskinen, P.K., Kallio, E.A., Tikkanen, J.M., Sihvola, R.K., Hayry, P.J., Lemstrom, K.B., 1999. Cytomegalovirus infection and cardiac allograft vasculopathy. Transpl. Infect. Dis. 1 (2), 115-126.

Lawson, C.M., 2000. Evidence for mimicry by viral antigens in animal models of autoimmune disease including myocarditis. Cell. Mol. Life Sci. 57 (4), 552-560.

Lee, S.H., Webb, J.R., Vidal, S.M., 2002. Innate immunity to cytomegalovirus: the Cmv1 locus and its role in natural killer cell function. Microbes Infect. 4 (15), 1491-1503.

Lipes, J., Skamene, E., Newkirk, M.M., 2002. The genotype of mice influences the autoimmune response to spliceosome proteins induced by cytomegalovirus gB immunization. Clin. Exp. Immunol. 129 (1), $19-26$.

Lunardi, C., Bason, C., Navone, R., Millo, E., Damonte, G., Corrocher, R., Puccetti, A., 2000. Systemic sclerosis immunoglobulin G autoantibodies bind the human cytomegalovirus late protein UL94 and induce apoptosis in human endothelial cells. Nat. Med. 6 (10), 1183-1186.

Matthes-Martin, S., Aberle, S.W., Peters, C., Holter, W., Popow-Kraupp, T., Potschger, U., Fritsch, G., Ladenstein, R., Rosenmayer, A., Dieckmann, K., Gadner, H., 1998. CMV-viraemia during allogenic bone marrow transplantation in paediatric patients: association with survival and graft-versus-host disease. Bone Marrow Transplant. 21 (Suppl. 2), S53-S56.

Michelson, S., Tardy-Panit, M., Colimon, R., Landini, M.P., 1989. A human cytomegalovirus-neutralizing monoclonal antibody recognizes a normal cell protein. J. Gen. Virol. 70 (Pt. 3), 673-684

Naucler, C.S., Larsson, S., Moller, E., 1996. A novel mechanism for virusinduced autoimmunity in humans. Immunol. Rev. 152, 175-192.

Nieto, F.J., Adam, E., Sorlie, P., Farzadegan, H., Melnick, J.L., Comstock, G.W., Szklo, M., 1996. Cohort study of cytomegalovirus infection as a risk factor for carotid intimal-medial thickening, a measure of subclinical atherosclerosis. Circulation 94 (5), 922-927.

O'Connell, K.A., Edidin, M., 1990. A mouse lymphoid endothelial cell line immortalized by simian virus 40 binds lymphocytes and retains functional characteristics of normal endothelial cells. J. Immunol. 144 (2), 521-525.

Pandey, J.P., LeRoy, E.C., 1998. Human cytomegalovirus and the vasculopathies of autoimmune diseases (especially scleroderma), allograft rejection, and coronary restenosis. Arthritis Rheum. 41 (1), $10-15$.

Pasqualini, R., Koivunen, E., Kain, R., Lahdenranta, J., Sakamoto, M., Stryhn, A., Ashmun, R.A., Shapiro, L.H., Arap, W., Ruoslahti, E., 2000. Aminopeptidase $\mathrm{N}$ is a receptor for tumor-homing peptides and a target for inhibiting angiogenesis. Cancer Res. 60 (3), $722-727$.

Phillips, A.J., Tomasec, P., Wang, E.C., Wilkinson, G.W., Borysiewicz, L.K., 1998. Human cytomegalovirus infection downregulates expression of the cellular aminopeptidases CD10 and CD13. Virology 250 (2), $350-358$.

Plakidou-Dymock, S., Tanner, M.J., McGivan, J.D., 1993. A role for aminopeptidase $\mathrm{N}$ in $\mathrm{Na}(+)$-dependent amino acid transport in bovine renal brush-border membranes. Biochem. J. 290 (Pt. 1), 59-65.

Presti, R.M., Pollock, J.L., Dal Canto, A.J., O’Guin, A.K., Virgin, H.W.t., 1998. Interferon gamma regulates acute and latent murine cytomegalovirus infection and chronic disease of the great vessels. J. Exp. Med. 188 (3), 577-588.

Riemann, D., Kehlen, A., Langner, J., 1999. CD13-Not just a marker in leukemia typing. Immunol. Today 20 (2), 83-88.

Soderberg, C., Giugni, T.D., Zaia, J.A., Larsson, S., Wahlberg, J.M., Moller, E., 1993a. CD13 (human aminopeptidase N) mediates human cytomegalovirus infection. J. Virol. 67 (11), 6576-6585.

Soderberg, C., Larsson, S., Bergstedt-Lindqvist, S., Moller, E., 1993b. Definition of a subset of human peripheral blood mononuclear cells that are permissive to human cytomegalovirus infection. J. Virol. 67 (6), $3166-3175$.

Soderberg, C., Larsson, S., Rozell, B.L., Sumitran-Karuppan, S., Ljungman, P., Moller, E., 1996a. Cytomegalovirus-induced CD13-specific autoimmunity-A possible cause of chronic graft-vs-host disease. Transplantation 61 (4), 600-609.

Soderberg, C., Sumitran-Karuppan, S., Ljungman, P., Moller, E., 1996b. CD13-specific autoimmunity in cytomegalovirus-infected immunocompromised patients. Transplantation 61 (4), 594-600.

Stoddart, C.A., Cardin, R.D., Boname, J.M., Manning, W.C., Abenes, G.B., Mocarski, E.S., 1994. Peripheral blood mononuclear phagocytes mediate dissemination of murine cytomegalovirus. J. Virol. 68 (10), $6243-6253$.

Swihart, K., Fruth, U., Messmer, N., Hug, K., Behin, R., Huang, S., Del Giudice, G., Aguet, M., Louis, J.A., 1995. Mice from a genetically resistant background lacking the interferon gamma receptor are susceptible to infection with Leishmania major but mount a polarized $\mathrm{T}$ helper cell 1-type CD4+ T cell response. J. Exp. Med. 181 (3), 961-971.

Tirado, S.M., Yoon, K.J., 2003. Antibody-dependent enhancement of virus infection and disease. Viral Immunol. 16 (1), 69-86.

Vijgen, L., Keyaerts, E., Zlateva, K., Van Ranst, M., 2004. Identification of six new polymorphisms in the human coronavirus $229 \mathrm{E}$ receptor gene (aminopeptidase N/CD13). Int. J. Infect. Dis. 8 (4), 217-222.

Wang, X., Huong, S.M., Chiu, M.L., Raab-Traub, N., Huang, E.S., 2003. Epidermal growth factor receptor is a cellular receptor for human cytomegalovirus. Nature 424 (6947), 456-461.

Watanabe, S., 1998. The receptor and pathways for human cytomegalovirus entry. Nippon Rinsho 56 (1), 44-49. 
Wentworth, D.E., Holmes, K.V., 2001. Molecular determinants of species specificity in the coronavirus receptor aminopeptidase $\mathrm{N}$ (CD13): influence of N-linked glycosylation. J. Virol. 75 (20), 9741-9752.

Wright, J.F., Kurosky, A., Pryzdial, E.L., Wasi, S., 1995. Host cellular annexin II is associated with cytomegalovirus particles isolated from cultured human fibroblasts. J. Virol. 69 (8), 4784-4791.

Yeager, C.L., Ashmun, R.A., Williams, R.K., Cardellichio, C.B., Shapiro,
L.H., Look, A.T., Holmes, K.V., 1992. Human aminopeptidase N is a receptor for human coronavirus 229E. Nature 357 (6377), 420-422.

Yu, X.J., Luo, C., Lin, J.C., Hao, P., He, Y.Y., Guo, Z.M., Qin, L., Su, J., Liu, B.S., Huang, Y., Nan, P., Li, C.S., Xiong, B., Luo, X.M., Zhao, G.P., Pei, G., Chen, K.X., Shen, X., Shen, J.H., Zou, J.P., He, W.Z., Shi, T.L., Zhong, Y., Jiang, H.L., Li, Y.X., 2003. Putative hAPN receptor binding sites in SARS_CoV spike protein. Acta Pharmacol. Sin. 24 (6), $481-488$ 